\title{
O Jnteracionismo Sociodiscursivo na Formação dos Professores: O Perigo da Gramaticalização dos Gêneros Textuais
}

\author{
Marcos BALTAR \\ Fabiele Stockmans DE NARDI \\ Luciane Todeschini FERREIRA \\ Maria Eugênia GASTALDELLO \\ Universidade de Caxias do Sul
}

\begin{abstract}
Resumo: Este trabalho busca oferecer subsídios para a discussão acerca do ensino de língua materna, que vem sendo questionado ao longo de décadas, mas que ainda não tem apresentado o retorno que a nossa sociedade deseja, haja vista os resultados recentes de avaliações internacionais e nacionais, com a participação de alunos de ensino fundamental e médio. Trata-se de uma reflexão sobre como estão atuando em sala de aula, hoje, os professores de Língua Materna; sobre quais os pressupostos teóricos que os têm orientado, qual visão de língua e sociedade que estão lhe servindo de base para o planejamento de suas aulas e quais seriam as teorias e pedagogias mais coerentes para mudar o quadro. As constatações e sugestões que apresentaremos a seguir têm origem em uma pesquisa-ação realizada com professores da rede pública municipal de Ensino Fundamental, nos últimos dois anos, na cidade de Caxias do Sul- RS.

Palavras-chave: Formação de professores; Gêneros textuais; Projetos Pedagógicos; Gramaticalização.
\end{abstract}

\begin{abstract}
In this article we offer elements to the discussion of the mother language teaching. Althoug this discussion have beeing done during last decade, the advances and practical results that are expected by society are not significant. The poor performance of Brazilian undergraduate students in national and international examinations withstands this affirmation. We focus mother tongue teachers acting in the classroom. What are the theorethical bases of their teaching? What
\end{abstract}


are their comprehension of language and society and how this comprehension affects their teaching? Finally we argue which is the most suitable pedagogy to face this questions and change the situation. The findings presented here were originated in a research project performed with teachers of basic levels in municipal schools of Caxias do Sul, state of Rio Grande do Sul.

Resumen: Este trabajo desea ofrecer elementos para la discusión sobre la enseñanza de lengua materna, una vez que ella, aunque haya sido cuestinada a lo largo de décadas, no logró, hasta el momento, regalar a la sociedad las respuestas que ella necesita. Eso se puede comprobar si hecharmos un vistazo a los resultados que fueron obtenidos recientemente por estudiantes de la enseñanza fundamental y mediana que realizaron evaluaciones nacionales e internacionales. Lo que proponemos, respecto a este cuadro, es una reflexión sobre la forma cómo están actuando en sala de clases los profesores de Lengua Materna; sobre qué presupuestos teórios los están orientando, qué visión de lengua y sociedad les sirven de base para el planeamiento de sus clases y cuáles serian las teorías y pedagogías más coerentes para que se pueda cambiar dicha realidad. Las constataciones y sugerencias que presentaremos en este artículo se originaron en una pesquisa-acción realizada en los últimos dos años con los profesores de la red pública municipal de enseñanza fundamental de la ciudad de Caxias do Sul RS.

Palabras-clave: Formación de profesores - Gêneros textuales Projectos Pedagógicos - Gramaticalización.

\section{Introdução}

Desde 1998, trabalhamos em formação permanente de professores de Língua Materna. De lá para cá tivemos a oportunidade de dialogar com uma centena de professores da educação básica acerca de seu trabalho na escola e na sala de aula. Encontramos resistência da parte de muitos; mas encontramos também professores sequiosos por mudança de sua prática. Todos com os quais nos deparamos demonstram estarem convencidos de que podem oferecer aulas mais interessantes, que de fato colaborem para desenvolver em seus alunos 
as competências necessárias para interagirem na sociedade em que vivem. Todos querem fazer de seus alunos bons leitores e bons escritores de textos em nossa Língua Portuguesa. Entretanto o desafio que sempre vem à tona é como fažer isso...

Diversas abordagens foram desenvolvidas nos últimos anos, no que diz respeito ao ensino da leitura e produção de textos. Bonini (2002) apresenta importante estudo em que divide, desde a década de 60 até hoje, quatro abordagens: retórico-lógica-textualcomunicativa- textual-psicolingüística - interacionista.

Em nossa pesquisa-ação buscamos, inicialmente, saber em que abordagem teórica os professores de língua materna que fazem parte do UCS-Produtore ${ }^{1}$ estavam embasados para organizarem seu trabalho nas escolas em que atuam, na cidade de Caxias do Sul, no nível do Ensino Fundamental. Constatamos a priori que os professores careciam de maior clareza acerca da concepção teórica em que se baseava a sua prática. A maioria que se inscreveu no projeto buscava práticas novas e interessantes para o trabalho com o texto em sala de aula, entretanto, ainda pairava a dúvida de como fazer isso sem abdicar do trabalho com os conteúdos já estabelecidos de um ano para o outro, centrado nas unidades da gramática da língua, quase sempre sob a ótica da prescrição e da normatização.

Notamos que alguns professores buscavam a saída para esse dilema a partir do trabalho com o texto. Embora dissessem estarem ancorados nos pressupostos da Lingǘstica Textual, organizavam sua metodologia trabalhando nos textos, inclusive os literários, as unidades da gramática da língua. Sobre esse tema Brandão (2002), entre outros autores, alerta que muitos professores deram enfoque equivocado à Lingüística Textual ao utilizarem o texto como um pretexto para o trabalho descontextualizado da gramática.

Nossa proposta, então, foi de tentar preencher essa lacuna, discutindo com os professores do projeto quais pressupostos teóricos dariam conta de organizar uma pedagogia mais eficiente para o desenvolvimento das competências de seus alunos. No intuito de

\footnotetext{
${ }^{1}$ Projeto de pesquisa-ação, coordenado pelo prof. Dr. Marcos Baltar que envolve pesquisadores do Departamento de Letras da UCS e professores da SMED de Caxias do Sul.
} 
encaminhar práticas escolares e de sala de aula mais potentes para equacionar tais problemas, escolhemos o embasamento teórico do Interacionismo sociodiscursivo (ISD), notadamente a partir de Bronckart (1999).

Esse trabalho que ora apresentamos relata duas experiências que estamos empreendendo com os professores do UCSProdutore: o trabalho com a produção de Jornal de Sala de Aula e o trabalho com o Circuito dos Gêneros. Ambos, à luz do Interacionismo sociodiscursivo, dedicam-se ao ensino da leitura e da produção de textos a partir da apropriação de gêneros textuais. Essa prática pedagógica do trabalho com os gêneros textuais nas escolas está se tornando cada vez mais freqüente, o que pode gerar (pela repetição irrefletida e, por vezes, pelo desconhecimento de referencial teórico que sustenta essa prática) alguns equívocos, entre os quais gostaríamos de chamar a atenção para o perigo da gramaticalização dos gêneros, tal como já ocorreu com o trabalho com o texto na perspectiva da Lingüística Textual.

Nosso enfoque, seguindo os ditames do ISD, é o de tratar o trabalho com os gêneros como um meio para o desenvolvimento de uma Competência Discursiva ${ }^{2}$ e não como um fim em si próprio, derivando para uma vertente apenas descritivista e classificatória dos gêneros textuais.

Nesse artigo, primeiramente, apresentaremos um quadro de como atuam alguns professores de Língua Materna. A seguir, analisaremos como vem sendo organizado o trabalho com o texto a partir da Lingüística Textual e como pode ser organizado esse trabalho a partir do Interacionismo sociodiscursivo. Por fim, ilustraremos o que vem sendo desenvolvido no UCS-Produtore, apresentando um breve relato de duas atividades teórico-pedagógicas construídas em conjunto com os professores envolvidos no projeto.

1 Um Quadro do Ensino de Língua Materna: Como Atuam Alguns Professores e Como Foram Formados

Embora se discuta nas escolas, e nos cursos de Letras de todo o país, já há algum tempo, os problemas que envolvem o ensino

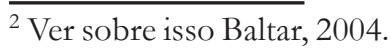


de Língua Materna, muitos professores, que estão atuando nas salas de aula das escolas brasileiras, hoje, ainda não conseguem se desprender de uma prática ancorada na gramática. Isso significa dizer que o que se faz é um trabalho dissociado do desenvolvimento da competência discursiva, que implicaria a apropriação pelo usuário da língua dos diversos gêneros textuais que circulam na sociedade para com isso poder interagir em diferentes situações do cotidiano.

Vale ressaltar que o que a maioria tem feito em sala de aula está diretamente associado ao que aprendeu no curso de Letras que freqüentou, cujos currículos foram elaborados sob a ótica da abordagem tradicional, o que se refletiu na organização de programas em que o ensino de língua materna baseava-se, ainda, num trabalho com a frase e não com o tex to como unidade maior da língua; portanto sua prática reflete a sua formação.

Todavia, muitos professores, que além de sua graduação em Letras, freqüentam os cursos de formação, ou de pós-graduação, notadamente em nível de especialização, têm a consciência da necessidade de que caminhos diferentes daquele do ensino da transmissão/prescrição do que é certo e errado na língua sejam adotados, pois ali se discutem teorias que suplantariam o ensino exclusivamente gramatical, como, por exemplo, a Lingüística Textual. Entretanto, o que temos observado com relação à prática desses últimos é um trabalho ainda centrado nos ditames da gramática, só que apresentado de outra forma. O que antes era abordado no nível da palavra ou da frase, agora é feito a partir do texto. Trabalha-se então com textos como pretexto para ensinar os conteúdos curriculares. ${ }^{3}$

\section{O Trabalho com o Texto em Sala de Aula: o Caminho da Lingüística Textual}

A partir da metade do século que passou, surgiu na Europa uma corrente lingüística denominada de Lingüística Textual, que, diferentemente do Estruturalismo Saussuriano e do Gerativismo Chomskyano, concebe como objeto de estudo da língua não mais

\footnotetext{
${ }^{3}$ Ver carta de Mário Prata ao Ministro da Educação, sobre a utilização de sua crônica As Meninas-Moça, no vestibular.
} 
suas estruturas, tampouco sua propriedade geradora de frases, e começa a tratar da questão de sua unidade coesa e coerente denominada texto, o que, sem dúvida, representa um grande avanço no enfoque de ensino de língua. Um exemplo disso é que o ensino pode libertar-se da prática mnemônica da gramática tradicional, que exige do aluno conhecimentos metalingüísticos. Esse ensino, baseado nas regras gramaticais, que, como já alertamos, gera o problema sério da insegurança no trato da Linguagem causado pelo medo de errar.

O trabalho com o texto, em princípio, deveria escapar dessa prática, pois pressupõe o exercício de pensar, de tomar decisões sobre as formas possíveis de expressar o que se quer dizer, de modo coeso e coerente, de acordo com os efeitos de sentido que se pretende em relação ao interlocutor; pressupõe o exercício de criar estratégias, de mobilizar conhecimentos prévios para poder materializar em linguagem o que se pretende dizer ou, então, desvendar o que está sendo dito, numa relação entre autor texto e leitor. No lugar da prática de memorizar as regras da norma gramatical para fazer um teste de conhecimentos sobre a língua ou para escrever certo uma redação escolar, o professor de língua, através da prática da leitura e da produção textual, poderá instrumentalizar seu aluno para antes de tudo perceber o meio em que está inserido, e com isso poder expressar-se, soltar sua voz nesse meio.

Outra ganho relevante que se pode obter quando se trabalha com textos advém da escolha de textos autênticos que circulem na sociedade. Trabalhar com alunos de Ensino Fundamental e Médio apenas a partir de textos literários pode causar efeitos negativos, provocando aversão à leitura, restringindo o prazer do aprendiz de entrar no ambiente discursivo literário. Principalmente se o uso dos textos de literatura vier a serviço de exercícios gramaticais. Além disso, há a questão da escolha das temáticas das obras em relação à idade e ao interesse dos alunos. Naturalmente que romances, crônicas e contos do século passado podem ser trabalhados e até comparados estilisticamente com os escritos hoje, quando se quer fazer uma imersão no ambiente discursivo literário. Mas o trabalho com suportes textuais do cotidiano, com os textos de revistas e de jornais, não pode ser desprezado, haja vista a aproximação da atividade de linguagem com a realidade dos alunos. Enfim, todos os textos que circulam na sociedade 
podem ser levados para as salas de aula desde que se tenham claros os propósitos.

\section{A Formação dos Professores e o Interacionismo Sociodiscursivo}

Nossa proposta de ensino de língua, ancorada nos pressupostos teóricos do Interacionismo sociodiscursivo, visa estender a prática do trabalho com o texto como uma mera redação escolar, ou como a aplicação de regras de gramática, para a prática do trabalho com a diversidade dos gêneros textuais produzidos ao longo da história que estão disponíveis no arquitexto/intertexto para serem atualizados à medida que os usuários da língua entrem em interação social através da linguagem. Trata-se de um trabalho com os mais variados textos que circulam nos mais variados ambientes discursivos da sociedade. Trata-se, também, de um ensino dos textos a partir da análise de suas dimensões cotextual: composição infra-estrutural, modalidades discursivas predominantes, seqüências textuais a serviço da textualização; e contextuais: os ambientes discursivos, os suportes textuais em que ocorrem as atividades de linguagem, o papel dos interlocutores na interação e a situação de enunciação. Essa compreensão de quais textos circulam na sociedade, de quais são suas características e quais seus efeitos na interação social entre os usuários da língua é condição sine qua non para que os professores, na sua atuação como mediadores dos trabalhos de leitura e releitura e de escrita e de reescrita desses textos, possam ajudar seus alunos a desenvolverem sua Competência Discursiva.

Bronckart (1999), num quadro da psicologia da linguagem, inspirado na proposição interacionista da ação de linguagem, pensamento e consciência de Vygotsky (1985), baseado na teoria do agir comunicativo de Habermas (1987), na interação verbal dialógica de Bakhtin (1997), nas formações discursivas de Foucault (1969), na concepção de linguagem como produto de interação social e do uso no jogo das relações entre os usuários da língua de Wittgenstein (1961), propôs um amálgama teórico o qual denominou de Interacionismo sociodiscursivo, em que postula que as ações bumanas devem ser tratadas em suas dimensões sociais e discursivas constitutivas. Considera a linguagem como 
uma característica da atividade social dos homens, que interagem no intuito de se comunicar, através de atividades e de ações de linguagem. São estas atividades de linguagem, que podem ser também consideradas como eventos discursivos (unidades sociológicas, coletivas) dentro de zonas de cooperação social determinadas, os lugares sociais ou ainda os lugares das formações sociais discursivas, e que são o princípio constitutivo das ações de linguagem (unidades psicológicas, individuais), imputadas aos usuários da língua, organizadas em torno de unidades verbais: os textos e os discursos.

Referindo-se às manifestações empiricamente observáveis das ações de linguagem, Bronckart (1999) utiliza o termo gêneros textuais para falar das estruturas relativamente estáveis que estão disponíveis no arquitexto/intertexto e que podem ser atualizadas pelos interlocutores, quando estão diante de uma atividade de linguagem; e usa o termo tipo de discurso para falar dos efeitos de sentido que estão associados a dois mundos: narrar e expor, e que compõem os gêneros textuais.

O autor genebrino assevera que toda produção lingüística é uma ação social situada, levada a efeito por indivíduos singulares em formações sociais específicas. Além disso, declara que as únicas manifestações empiricamente observáveis das ações de linguagem humanas são os textos e os discursos que se apresentam como forma de ação social.

Esse quadro teórico apresentado por Bronckart (1999) abre grande possibilidade para os professores de língua materna trabalharem textos com seus alunos e com isso promoverem nas suas escolas a competência discursiva. $\mathrm{O}$ acesso aos diversos gêneros de textos que estão circulando na sociedade, como leitores responsivos e como produtores, possibilita quebrar o paradigma do ensino monológico da redação escolar e das aulas de gramática normativa. Isso lhes permitirá gradativamente ler e escrever os textos que necessitam saber para interagirem socialmente: desde um bilhete até uma carta de pedido de emprego. De uma resenha até um artigo científico. De uma receita até um manual de instruções. De um boletim de ocorrência a uma procuração. Desse modo, o acesso à norma culta da língua pode se dar de forma paulatina e segura, consciente e sem traumas, a partir da leitura e da releitura; da escrita e da reescrita dos mais variados 
textos. Caberá, então aos professores abrir sua sala de aula para o trabalho com todos os gêneros textuais possíveis, podendo inclusive contar com seus alunos para a escolha daqueles mais convenientes, segundo o programa da disciplina em cada série.

\section{A Formação dos Professores e a Pedagogia de Projetos: Duas Experiências Possíveis de Serem Realizadas}

Conforme Hernández (1998), o melhor jeito de organiżar o currículo escolar éporprojetos didáticos. Essa corrente pedagógica tem como principal característica uma mudança de paradigma em que o foco de interesse deixa de ser exclusivamente o ensino e passa a ser a aprendizagem. Isto é, preocupa-se mais em entender como o sujeito é capaz de construir seus saberes na interação social com o outro. A partir desta nova concepção fala-se hoje em dia em ensinoaprendizagem como um contínuo de atitudes pedagógicas associadas, em que as responsabilidades pelo sucesso da prática pedagógica estão divididas entre os educadores e os educandos. Chegou-se ao entendimento de que é necessário diminuir a distância entre o modo de aprendizagem escolar e o modo de aprendizagem social. Nesta perspectiva, o processo da aprendizagem passa a ter mais importância do que o produto. Isso implica outro relacionamento, outro tipo de interação entre professores e alunos, entre escola e sociedade. Esse enfoque também modifica a condução das atividades de avaliação dos trabalhos. Acentua-se mais a avaliação auto-regulada e formativa.

Os alunos que participam da elaboração e da execução de um projeto sentem-se mais envolvidos e mais motivados, porque querem ter o prazer, o sabor da realização, algo inerente ao ser humano que vive em sociedade. $\mathrm{O}$ aspecto da participação de um coletivo é motivacional na formação dos alunos e está presente neste tipo de atividade. Trabalhar engajado num projeto funciona como que se a classe assinasse um contrato de empreendimento e soubesse que precisará executá-lo para depois socializá-lo, ou seja, mostrá-lo fora da sala de aula ou até mesmo fora da escola, quando possível, dependendo da característica da atividade.

Com a pedagogia de projetos, a heterogeneidade da turma, que no programa de disciplina comum gera, às vezes, 
dificuldades para o professor dimensionar a progressão de seu programa de ensino, conta como um fator positivo, como um enriquecimento ao processo e ao produto final, pois cada aluno colocará à disposição do projeto um pouco de sua experiência, segundo a atividade que lhe foi destinada pela coordenação dos trabalhos. Os papéis e as responsabilidades podem ser alterados para que todos somem saberes e aprendizagens aos seus conhecimentos iniciais.

Além do fator motivacional do aluno, a prática de projetos também traz outros efeitos positivos como o desenvolvimento de competências organizacionais e relacionais, tais como a noção de divisão de tarefas e de relação entre o todo e as partes.

No que diz respeito ao ensino-aprendizagem de textos, os professores de todas as áreas, mas principalmente os de língua materna, conhecendo a pedagogia de projetos, têm a oportunidade de trabalhar com atividades de linguagem significativas para seus alunos, uma vez que os alunos escreveriam e leriam em função de objetivos concretos.

Um exemplo disso é a produção de um Jornal de Sala de Aula (BALTAR, 2004). Trata-se de uma maneira concreta de envolver os alunos em uma situação de comunicação real, em que haverá alunos-escritores de fato que escreverão textos para serem publicados e lidos por alunos-leitores reais. É, também, uma maneira concreta de envolver toda a comunidade escolar: pais, alunos, professores e funcionários. A materialização de um suporte textual, tal qual um Jornal de Sala de Aula ou um Jornal Escolar, em princípio, pode garantir a voz de todos dentro da escola. Além do exercício da escrita e reescrita de textos, uma experiência com um projeto dessa natureza cumpre com a função de promover a interação entre os sujeitos de um determinado ambiente discursivo, o que amplia a possibilidade do desenvolvimento de todo o tipo de competência, além da competência discursiva.

Em nosso projeto de pesquisa-ação desenvolvemos esse trabalho com os professores da rede municipal de Caxias do Sul. A atividade foi realizada por meio de oficinas pedagógicas cujo intuito era sensibilizá-los para a importância e a potencialidade do trabalho com gêneros textuais em sala de aula e capacitá-los para a implementação desse projeto junto aos alunos da rede. 
O ponto de partida dessa atividade de linguagem é a construção do projeto de trabalho no qual são delineadas as etapas a serem seguidas para a construção do jornal. Daí a importância de se definir, por exemplo, as seções que serão contempladas e o formato que terá esse jornal. Para que essa etapa seja bem sucedida, um dos procedimentos viáveis é a exposição dos aprendizes aos modelos, que deverão ser por eles discutidos e analisados, partindo da identificação dos jornais que circulam na região a que pertencem e da linha editorial por eles seguida; discussão cuja finalidade maior é desenvolver nesses aprendizes uma consciência crítico-reflexiva acerca do papel da mídia na sociedade, reflexão que torna a atividade de leitura e produção textual realmente significativa.

Depois da análise desse suporte textual que é o jornal, ${ }^{4} \mathrm{de}$ suas seções e dos gêneros que podem integrá-las, sugere-se que os professores deliberem, junto com seus alunos, as seções e os gêneros que por eles serão produzidos, seguindo-se a isso o trabalho com as seqüências didáticas (SCHNEWLY; DOLZ, 2004, p. 95-128). para a apropriação desses gêneros. Após os professores terem vivenciado a construção do jornal na oficina, o trabalho culmina com a produção de um jornal nas escolas de origem desses professores. No conjunto dessas atividades, destaca-se a análise coletiva da experiência vivenciada pelos professores. Em nossa experiência, constatamos, a partir dessa análise, que, além dos ganhos previstos com a apropriação dos gêneros textuais jornalísticos, outras habilidades, de ordem cognitivo-interativas, vieram à tona.

O trabalho com diferentes gêneros também pode ser desenvolvido por meio da realização do Circuito dos Gêneros, uma atividade simples que, ao simular situações reais de comunicação, leva os alunos à produção de diferentes gêneros textuais. O Circuito é desencadeado pela leitura e análise de um texto gerador, a partir do qual os alunos são levados a pensar nos diferentes gêneros que poderiam ser produzidos. Eles partem, então, para a produção do gênero escolhido, trabalho inicial que desencadeará as diferentes reescritas, possibilitando que o aluno revise o próprio texto, adequando-o às exigências do gênero textual e do ambiente discursivo a que corresponde.

\footnotetext{
${ }^{4}$ A descrição minuciosa dessa atividade pode ser encontrada em Baltar (2004, p. 107-129).
} 
Uma experiência inicial foi feita com um conto de Ítalo Calvino, ${ }^{5}$ chamado o Tratamento com vespas, a partir do qual os alunos foram levados a produzir gêneros muito variados, transitando por diversos ambientes discursivos, passando da carta ao anúncio publicitário, da notícia de jornal à bula farmacêutica, entre outros. $\mathrm{O}$ elemento gerador, nesse caso, era o enredo e as relações nele estabelecidas entre os personagens. Esses ingredientes forneciam aos alunos os contornos necessários para que eles determinassem as condições de produção da atividade de linguagem que iriam desenvolver, tendo condições de precisar desde os objetivos específicos dessa atividade até os lugares sociais ocupados pelos sujeitos nela envolvidos, o que os inseria em uma situação real de comunicação, fornecendo-lhes elementos consistentes para a produção do gênero em questão.

Ao serem envolvidos em atividade como o Circuito dos Gêneros, os alunos não só reconhecem as condições de produção de um gênero e sua importância para a configuração que ele terá, como experimentam situações de enfrentamento para o desenvolvimento de sua capacidade cognitiva, uma vez que são colocados diante do desafio de criar múltiplos cenários representativos dos quais deriva a sua produção textual. Atividades dessa natureza cumprem uma dupla função: promovem tanto o aprendizado quando o desenvolvimento da competência cognitivo-discursiva do aprendiz.

\section{Considerações finais}

Enfim, de acordo com o quadro que apresentamos, a partir da observação de práticas de sala de aula, da participação dos professores em seminários e oficinas, trazemos como síntese desse trabalho a proposição de que os professores de Língua Materna tenham ciência e busquem apropriar-se das teorias que lhes permitam promover a interação sociodiscursiva de seus alunos nos ambientes em que atuam em sociedade. Procuramos alertar para a inadequação do trabalho com o texto como um fim em si mesmo; prática

\footnotetext{
${ }^{5} \mathrm{~A}$ referência completa do texto e a descrição da atividade podem ser encontradas no site <http://www.ucs.br/cchc/dele/ucs-produtore>.
} 
descritivista ou prescritivista que poderia resultar em uma gramaticalização dos gêneros textuais. Diferentemente disso, procuramos construir com os professores do UCS-Produtore um trabalho com textos/ gêneros textuais, partindo, sempre que possível, de atividades de linguagem significativas, que possibilitem a interação sociodiscursiva entre os usuários da língua. Aos professores mediadores dessas atividades de linguagem, sugerimos a tarefa de expor seus alunos à gama diversificada dos gêneros textuais que existem na sociedade, nos diferentes ambientes discursivos, com suas estruturas relativamente estáveis, organizados pelas diversas modalidades discursivas, para que com isso possam se apropriar desses gêneros como instrumentos de interação social.

Trouxemos, como exemplos de práticas significativas para o desenvolvimento da Competência Discursiva dos alunos, duas experiências possíveis de serem implementadas pelos professores de língua materna em suas escolas: o Jornal de Sala de Aula ou Jornal escolar e o Circuito dos gêneros. Nessas experiências procuramos demonstrar o quanto os professores podem ser desafiados para implementarem em suas escolas atividades de linguagem que resultem em práticas discursivas emancipatórias, que possibilitem, em última instância, um empoderamento de seus alunos para atuarem na sociedade da qual fazem parte.

\section{Referências}

BALTAR, M. A competência discursiva e os gêneros textuais: uma experiência com o jornal de sala de aula. Caxias do Sul: EDUCS, 2004.

Relatório do Projeto PROLABORE. Secretaria de Educação do estado do Tocantins, 1998.

BAKHTIN, M. Os gêneros do discurso. In: Estética da criação verbal. São Paulo: Martins Fontes, 1997. p. 277-299.

BONINI, A. Proposta metodológica para o ensino da leitura e da produção de textos: o papel da psicolingüística. 2002. Disponível 
em: <http://www.ucs.br/cchc/dele/ucs-produtore>inventário $>>$. Vários acessos.

BRONCKART, J. P. Atividade de linguagem, textos e discursos: por um interacionismo sociodiscursivo. São Paulo: EDUC, 1999.

BRANDÃO, H. N. Gêneros do discurso na escola. São Paulo: Cortez, 2002.

FOUCAULT, M. L’Archelogie du savoir. Paris: Gallimard, 1969.

HABERMAS, J. Théorie de l'agir communicationnel: rationalité de l'agir et rationalisation de la société. Tomo I. Paris: Fayard, 1987.

HERNÁNDEZ, F. Transgressão e mudança na educação: os projetos de trabalho. São Paulo: Artmed, 1998.

PRATA, Mario. O que é isso, Ministro Paulo Renato? 1999. Disponível em: < http://www.marioprataonline.com.br/obra/ cronicas/prata990616.html>. Vários acessos.

SCHNEUWLY, B.; DOLZ, J. Gêneros orais e escritos na escola. Campinas: Mercado de Letras, 2004.

VYGOTSKY, L. S. Pensée et language. Paris: Editions Sociales, 1985.

WITTGENSTEIN, L. Investigations philosophiques. Paris: Gallimard, 1961. 